\title{
Complicity and Simplexity
}

\author{
IAN STEWART \\ University of Warwick (UK)
}

I first met Jack Cohen in 1990. He'd been reading my book Does God Play Dice?, had some questions to ask me, and phoned to suggest we met to discuss them. We went to a local pub for lunch and left at about 4 o'clock.

One of the first questions that Jack asked me was "what do you call it when two separate systems kind of - " at this point he moved his hands in the air like someone climbing a rope "-interact recursively with each other so that both are changed beyond recognition?" I knew what he meant-evolution is a good example, where the "information" in genes interacts with the global ecosystem to select organisms that "work." But as far as I knew there wasn't a name for such behaviour.

After several years of pub lunches, we decided to put our ideas together in a book, The Collapse of Chaos. Idly musing about the words "complexity" and "simplicity." and their origins, two new words assembled themselves: "simplexity" and "complicity." Both can be found in the dictionary: the first is an obsolete form of the word "simplicity," while the second is in wide use.

We realised that the usual meaning of the word "complicity" comes pretty close to answering Jack's question, so we added some technical bells and whistles and made it one of the basic concepts in our book. Which left "simplexity" to describe another basic concept.

Simplexity is the emergence of simple features in a single complex system. An example is the gravitational field of Mars, which results from 
the separate fields of each subatomic particle in the Martian rocks and atmosphere. For many purposes we can think of Mars as a point particle with all of its mass in the same place. This approximation is good enough to get a space probe into Martian orbit-though not good enough to determine the orbit precisely. Simplexities are mathematical consequences of the underlying rules of a single complex system.

Complicity is more mysterious. An example is malaria. Here the interacting systems are the circulation of blood in the human body and the ability of mosquitoes to suck blood. When these systems simply interact, mosquitoes suck human blood, and that's it. However, this very interaction paves the way to new forms of behaviour. Parasites in the blood can be sucked up too, and transmitted to another human. The mere possibility of this "environmental niche" loads the evolutionary dice in favour of such a parasite appearing.

The important point here is that complicity is not mere interaction. Interaction just lets the mosquito suck blood. Complicity is a repeated process formed by many interactions, each changing the systems concerned and making further changes possible, so that after a while the combination of the two systems can do things that are present in neither.

Educators sometimes view the student as a receptacle and the teacher as a source of knowledge that is poured into the student drop by drop. But a vital aspect is missing here. Yes, the student is changed by the educational process-but so is the teacher. Education is another example of complicity.

\begin{abstract}
About the Author
Ian Stewart is a Professor in the Mathematics Institute of the University of Warwick and a Fellow of the Royal Society. He has published 180 research papers, mainly on dynamical systems and pattern formation. He has written more than 60 books, and is best known for his popular science writing, with books such as Does God Play Dice?, Letters to a Young Mathematician, and Why Beauty is Truth. Jointly with Jack Cohen he is the author of The Collapse of Chaos and Figments of Reality. [e-mail: i.n.stewart@warwick.ac.uk]
\end{abstract}

(C) Copyright 2007. The author, Ian Stewart, assigns to the University of Alberta and other educational and non-profit institutions a non-exclusive license to use this document for personal use and in courses of instruction provided that the article is used in full and this copyright statement is reproduced. The authors also grant a non-exclusive license to the University of Alberta to publish this document in full on the World Wide Web, and for the document to be published on mirrors on the World Wide Web. Any other usage is prohibited without the express permission of the author. 